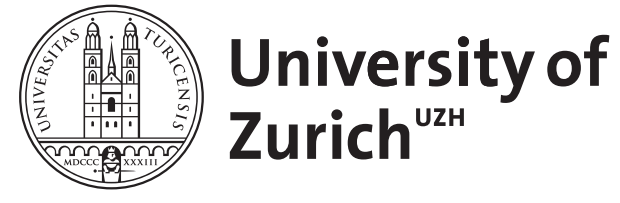

Zurich Open Repository and Archive

University of Zurich

University Library

Strickhofstrasse 39

CH-8057 Zurich

www.zora.uzh.ch

Year: 2009

\title{
Acceptance and therapeutic practice of controlled drinking as an outcome goal by Swiss alcohol treatment programmes
}

Klingemann, $\mathrm{H}$; Rosenberg, $\mathrm{H}$

DOI: https://doi.org/10.1159/000210041

Posted at the Zurich Open Repository and Archive, University of Zurich ZORA URL: https://doi.org/10.5167/uzh-31311

Journal Article

Published Version

Originally published at:

Klingemann, H; Rosenberg, H (2009). Acceptance and therapeutic practice of controlled drinking as an outcome goal by Swiss alcohol treatment programmes. European Addiction Research, 15(3):121-127.

DOI: https://doi.org/10.1159/000210041 


\title{
Acceptance and Therapeutic Practice of Controlled Drinking as an Outcome Goal by Swiss Alcohol Treatment Programmes
}

\author{
Harald Klingemann ${ }^{a}$ Harold Rosenberg $^{b}$ \\ a University of Zurich, Substance Use Disorders Unit (SUD), Zurich, Switzerland; b Bowling Green State University, \\ Bowling Green, Ohio, USA
}

Key Words

Controlled drinking $\cdot$ Harm reduction - Alcohol abuse •

Switzerland

\begin{abstract}
Sixty-one percent (138/226) of Swiss inpatient and outpatient alcohol treatment programmes responded to a postal survey designed to assess the definition and acceptance of controlled drinking $(C D)$ as a treatment objective, the degree to which a client's severity of dependence and finality of CD as an outcome goal were associated with acceptance, and the perceived value of selected client characteristics when making treatment recommendations. CD was acceptable to large proportions of both outpatient services and inpatient programmes, although willingness to recommend CD was associated with client characteristics such as selecting $C D$ as intermediate versus final outcome goal, lower severity of dependence, not being pregnant and higher social stability. Information and individual therapy to help clients pursue a $C D$ goal are commonly available in outpatient agencies and some inpatient programmes, but group counseling, cue exposure and wet house services are not typically available from Swiss programmes.

Copyright $\odot 2009$ S. Karger AG, Basel
\end{abstract}

Research conducted in North America, Western Europe and Australia has shown that the acceptance and implementation of controlled drinking (CD) as a treatment option/modality varies depending on the country, selected characteristics of the client (e.g. severity of dependence), and type of treatment setting (e.g. outpatient vs. inpatient). For example, a survey conducted in the United States revealed that abstinence is the predominant outcome goal prescribed for alcohol dependent and abusing clients in American inpatient detoxification, rehabilitation and halfway house programmes, although almost one half of the outpatient agencies responding to the survey reported moderate drinking as appropriate for at least a minority of their clientele [1]. Surveys of Canadian alcohol treatment counselors and administrators found that somewhat larger proportions of respondents endorsed nonabstinence goals compared to the United States $[2,3]$. Similar to the results of other surveys in other countries, acceptance rates in Canadian agencies varied by type of service, with those programmes treating more severely dependent clients (e.g. inpatient programmes, residential services, halfway houses) rejecting controlled drinking as an outcome goal more frequently than outpatient services.

\section{KARGER}

Fax +4161306 1234 E-Mail karger@karger.ch www.karger.com (c) 2009 S. Karger AG, Basel

$1022-6877 / 09 / 0153-0121 \$ 26.00 / 0$

Accessible online at:

www.karger.com/ear
Harald Klingemann

Route du village 17

CH-1134 Vufflens-le-Château (Switzerland)

Tel. +41 79478 7471, Fax +41 218032144

E-Mail harald.klingemann@bfh.ch 
Two surveys of Australian treatment services have reported widespread acceptance and application of controlled drinking. Specifically, both Donovan and Heather [4] and Dawe and Richmond [5] found that large majorities of outpatient or mixed inpatient-outpatient services endorsed controlled drinking, although only about one quarter of the residential services reported controlled drinking as acceptable. Surveys of British substance misuse agencies conducted over the past three decades have reported continuous acceptance of controlled drinking as a goal choice by about three quarters of a diverse set of programmes [6-8]. These assessments also revealed that controlled drinking was seen as appropriate for younger and less severely dependent clients, and that controlled drinking as an interim goal was more acceptable than as one's final outcome goal.

Studies in continental Europe include a survey of Norwegian alcohol treatment centers showing that $90 \%$ of respondents reported allowing outpatient clients to choose between abstinence and moderate drinking, and that $59 \%$ reported allowing inpatients a choice of outcome goals [9]. Although Körkel [10] did not administer a survey, his review of programmes in western Germany indicated that a controlled drinking goal was acceptable in a wide variety of alcohol treatment agencies. In an analysis of almost 15,000 patients registered in the Swiss national monitoring system from 1995 to 2001, Maffli et al. [11] found that fewer than one half (45\%) wanted lifelong abstinence, $19 \%$ wanted to achieve controlled drinking, and another $22 \%$ wanted to abstain temporarily before resuming drinking (the remaining 14\% were undecided or did not want to change their consumption at all).

The results of these studies reveal meaningful support for allowing less severely alcohol-dependent clients to choose controlled drinking as their interim or final outcome goal, although acceptance is more limited in residential facilities than outpatient or mixed services and is more limited in the United States than in other countries. The acceptance of CD is an outcome of several influences, including a preference for nonabstinence outcomes by consumers of alcoholism treatment services [11] and research demonstrating the effectiveness of CD interventions [e.g. 12]. Furthermore, given the unwillingness of some problem drinkers to accept an abstinence goal, some clinicians and policy makers have argued that offering controlled drinking attracts clients who are ambivalent about abstinence, but would benefit from therapy that reduced their consumption [13]. Moderate drinking may be viewed as a form of harm minimization to reduce the unhealthy medical, psychological, and social outcomes of ongoing alcohol abuse, although Heather [14] argued that the term 'harm reduction' should be reserved for interventions that emphasize decreasing problems resulting from consumption rather than on decreasing consumption itself.

Given the historical controversy regarding controlled drinking [15], the degree to which agencies around the world continue to allow clients to select controlled drinking as an outcome goal warrants continued empirical study. Therefore, to explore the degree to which Swiss treatment providers were accepting of CD goals and provided interventions designed to help clients achieve such goals, we mailed a questionnaire - based on those employed in previously conducted nationwide surveys in other countries - to every alcohol treatment agency in Switzerland. The questionnaire included questions to assess how respondents defined CD, whether acceptance of $\mathrm{CD}$ varied as a function of client severity and finality of goal, those client characteristics seen as relevant to goal choice, which harm reduction interventions were available, and what reasons influenced respondents' views of CD.

\section{Method}

\section{Participants}

Potential respondents were selected from the national online inventory of addiction treatment institutions 'DROGINDEX' (www.drogindex.ch) published by the Swiss Federal Office of Health (BAG) and the database of the Swiss coordinating agency for inpatient addiction programmes (www.koste.ch). The initial sample consisted of 324 agency directors to whom we sent the questionnaire during the first six months of 2005. Seventy-six agencies were eliminated from the list of potential respondents because they no longer operated $(n=7)$ or responded that they no longer offered alcohol treatment $(n=69)$. Of the remaining 248 agencies, responses from 29 agency directors who filled out one questionnaire for more than one agency within their umbrella organization revealed that the actual total of potential agencies totaled 226. Following 5 months of data collection, during which nonresponders were sent follow-up letters encouraging participation, we received usable responses from 138 of 226 agencies (response rate $=61 \%$ ).

Of the 138 respondents, $79 \%(n=109)$ of the questionnaires were filled out by the agency director or chief doctor; in the remaining $21 \%$, the task was delegated to a qualified staff member (e.g. staff psychologist, social worker). Almost one quarter ( $\mathrm{n}=$ 32) of the respondents filled out the questionnaire in consultation with their agency staff and $40 \%(n=55)$ reported having consulted documents and statistics when filling out the questionnaire. Of the 114 responding agencies from the German-speaking part of Switzerland, over one half were outpatient programmes $(57 \%, 65 / 114)$, whereas fewer than half of the respondents from 
French-speaking $(\mathrm{n}=18)$ and Italian-speaking regions $(\mathrm{n}=6)$ were outpatient programmes $(42 \%, 10 / 24)$. There was a wide variety of types of agencies in the sample; for example, a little over two fifths $(\mathrm{n}=59)$ treated substance abuse; almost one quarter $(\mathrm{n}=33)$ treated nonsubstance-related addictive behaviors, and almost one third $(n=44)$ offered counseling for both substance misuse and other problems. Consistent with this diversity in the types of agencies, the proportion of clients with a main, primary alcohol diagnosis varied from fewer than 20 to over $80 \%$. A comparison of the responding institutions against the total number of possible respondents by language region and type of programme shows only a slight over-representation of Swiss-German programmes in the sample ( $83 \%$ in sample vs. $79 \%$ in population) and of outpatient programmes ( $54 \%$ in sample vs. $51 \%$ in population). More details on further characteristics of participating institutions such as financing, target groups and professions can be found in the detailed research working report [16, section 2.3.1., pp 16-20].

\section{Questionnaire}

To facilitate comparison with previously published surveys of controlled drinking, the questionnaire used for this postal survey was based on the Alcohol Treatment Practices Questionnaire [1], the Alcohol \& Drug Treatment Practices Questionnaire [8] and the Alcohol Treatment Questionnaire [4]. To measure characteristics of the agencies, we also included items from the national monitoring questionnaire [Act-Info; 17].

In the introductory part of the questionnaire, respondents were instructed to consider the attitudes of the agency's therapeutic staff when answering the questions. The initial items on the questionnaire were open-ended questions designed to assess the respondents' definitions of both abstinence and CD. We then asked respondents to evaluate how acceptable or unacceptable they viewed $C D$ as function of the severity of the client's problem (alcohol misuse vs. alcohol dependence) and as a function of finality of CD as an outcome goal (intermediate objective on the way to abstinence vs. as final objective). For this question, we defined controlled drinking for respondents as disciplined drinking that followed a fixed drinking plan or drinking rules. Based on DSM-IV criteria, alcohol dependence was operationally defined as excessive drinking resulting in withdrawal, a significant increase of tolerance, and psychological urge to drink compulsively. Alcohol misuse was operationally defined for respondents as excessive drinking without experience of withdrawal, markedly increased tolerance or psychological urge to drink. The level of agreement over the treatment objectives was addressed by the question asking how acceptable it is that either the client, the therapist or both should set the objectives in the case of misuse and in the case of dependence (item No. 16).

The next section of the questionnaire asked respondents to rate the relevance of various client characteristics when considering whether to support a client's desire to pursue CD as a treatment objective. Respondents were next asked about the availability at their agency of 11 different types of services, including allowing CD depending on client severity and finality of outcome goal, individual and family counseling for $\mathrm{CD}$, cue exposure therapy, and drop-in services for intoxicated clients (i.e. wet house). Respondents then rated the degree to which various factors - including the disease model, research, professional experience, personal drinking experience, and agency philosophy - influenced whether or not they offered CD therapy. The questionnaire concluded with items inquiring about characteristics of the agency and the person who completed the questionnaire (copy of survey is available from the first author).

\section{Data Analyses}

Responses to the open-ended questions regarding definitions of CD and abstinence were coded by the first author for reporting of frequency counts. To test the association of acceptance and rejection of CD and type of programme (inpatient vs. outpatient), we conducted four separate $\chi^{2}$ tests within each of the four combinations of client severity and finality of outcome goal (CD as intermediate goal for alcohol misusers; $\mathrm{CD}$ as final goal for alcohol misusers; CD as intermediate goal for alcohol-dependent clients; CD as final outcome goal for alcohol-dependent clients). Frequency counts were calculated to assess which client characteristics were viewed as important when considering whether to support $\mathrm{CD}$, which $\mathrm{CD}$-related interventions were available in Swiss agencies, respondents' attributions for accepting and rejecting $\mathrm{CD}$, and sources of information on $\mathrm{CD}$. For data analysis, the Statistical Package for the Social Sciences SPSS v.16.0 was used.

\section{Results}

\section{Respondents' Definitions of 'Abstinence' and \\ 'Controlled Drinking'}

Over two-thirds (69\%) of the free-response definitions of CD made reference to one's 'amount of drinking', $36 \%$ made reference to a 'drinking plan' ( $3 \%$ specified the conditions included in a drinking plan), and $22 \%$ made reference to the value of negotiating or controlling $\mathrm{CD}$ as a treatment goal (totals greater than $100 \%$ because respondents could list multiple different definitions). The frequency with which a drinking plan was listed as a component of CD varied by type of programme, with $43 \%$ of outpatient respondents noting this feature compared to $28 \%$ of respondents working in inpatient programmes. The responses to the open-ended question asking respondents to define abstinence revealed that $53 \%$ of the respondents explicitly indicated, without attaching any further conditions or comments, that abstinence meant 'giving up alcohol consumption'. Only 29\% explicitly specified the duration of abstinence ( $14 \%$ as unlimited in time or meaning 'life-long abstinence'). Finally, 15\% of the respondents considered 'abstinence' to be a lifestyle.

\section{Acceptance or Rejection of CD by Severity of Alcohol Problem and Finality of Outcome Goal}

As examination of table 1 reveals, acceptance varied considerably, ranging from approximately one third to approximately four fifths of the respondents depending 
Table 1. Percent acceptance of controlled drinking (CD) by type of outcome, client severity and type of setting

\begin{tabular}{|c|c|c|c|c|c|c|c|c|}
\hline \multirow[t]{2}{*}{ How acceptable is ...: } & \multicolumn{2}{|c|}{$\begin{array}{l}\mathrm{CD} \text { as intermediate objective } \\
\text { on the way to total absti- } \\
\text { nence with alcohol misusers? }\end{array}$} & \multicolumn{2}{|c|}{$\begin{array}{l}\mathrm{CD} \text { as final objective } \\
\text { with alcohol misusers? }\end{array}$} & \multicolumn{2}{|c|}{$\begin{array}{l}\mathrm{CD} \text { as intermediate objective on } \\
\text { the way to total abstinence with } \\
\text { alcohol dependents? }\end{array}$} & \multicolumn{2}{|c|}{$\begin{array}{l}\mathrm{CD} \text { as final objective } \\
\text { with alcohol depen- } \\
\text { dents? }\end{array}$} \\
\hline & $\begin{array}{l}\text { inpatient } \\
(\mathrm{n}=62)\end{array}$ & $\begin{array}{l}\text { outpatient } \\
(\mathrm{n}=74)\end{array}$ & $\begin{array}{l}\text { inpatient } \\
(\mathrm{n}=62)\end{array}$ & $\begin{array}{l}\text { outpatient } \\
(\mathrm{n}=74)\end{array}$ & $\begin{array}{l}\text { inpatient } \\
(\mathrm{n}=62)\end{array}$ & $\begin{array}{l}\text { outpatient } \\
(\mathrm{n}=74)\end{array}$ & $\begin{array}{l}\text { inpatient } \\
(\mathrm{n}=62)\end{array}$ & $\begin{array}{l}\text { outpatient } \\
(\mathrm{n}=74)\end{array}$ \\
\hline Completely or somewhat unacceptable & 26 & 7 & 26 & 5 & 55 & 27 & 51 & 34 \\
\hline Neither acceptable nor unacceptable & 5 & 0 & 5 & 8 & 8 & 7 & 10 & 20 \\
\hline Somewhat or completely acceptable & 69 & 93 & 69 & 87 & 37 & 66 & 39 & 46 \\
\hline & \multicolumn{2}{|c|}{$\begin{array}{c}\chi^{2}=13.847 ; \text { d.f. }=2 \\
p=0.001\end{array}$} & \multicolumn{2}{|c|}{$\begin{array}{c}\chi^{2}=11.351 ; \text { d.f. }=2 \\
p=0.003\end{array}$} & \multicolumn{2}{|c|}{$\begin{array}{c}\chi^{2}=12.054 ; \text { d.f. }=2 \\
p=0.002\end{array}$} & \multicolumn{2}{|c|}{$\begin{array}{c}\chi^{2}=5.424 ; \text { d.f. }=2 \\
p>0.05\end{array}$} \\
\hline
\end{tabular}

on the client's severity of problem and finality of CD as an outcome goal. $\chi^{2}$ analyses (see table 1 , bottom row) also revealed that $\mathrm{CD}$ was typically more acceptable to respondents working for outpatient agencies versus those for inpatient programmes, and that $\mathrm{CD}$ was rated as more acceptable for alcohol misusers than for dependent drinkers by respondents working in both types of agencies.

We also examined whether acceptance of CD was associated with respondents' views regarding client autonomy. A bivariate Pearson correlation revealed that approval of $\mathrm{CD}$ as an outcome goal for alcohol misusers was correlated positively and significantly with level of agreement that alcohol misusers should define the objectives of their therapy (r.p. $=0.22, \mathrm{p}=0.011$ as a final outcome, and r.p. $=0.24, \mathrm{p}=0.006$ as intermediate outcome). We interpret this as indicating that recommendation of $\mathrm{CD}$ is associated not only with a client's severity and finality of $\mathrm{CD}$ as a goal, but also is associated with a broader attitude reflecting the value of self-determination by the client.

\section{Client Characteristics Considered Important when Considering whether to Support CD}

As examination of table 2 reveals, pregnancy in female clients, severity of dependence, criminal history, and social stability were rated as having at least a moderate if not important impact on support for a client's goal choice. Two client characteristics - gender and age - were rated almost uniformly as unimportant when considering whether a client was an appropriate candidate for CD regardless of the respondents' type of treatment setting. A client's family history of drinking problems was also rated as unimportant by a large proportion of respondents, although close to one third would support a client's CD goal only if there were no family history of alcohol prob- lems. Psychiatric history and deviant behavior were also seen as potential barriers to CD by some participants.

\section{Availability of CD-Related (and Other Harm \\ Reduction) Interventions in the Swiss Treatment \\ System}

As table 3 indicates, almost all services - including information on $\mathrm{CD}$, allowing $\mathrm{CD}$ as an outcome goal regardless of severity and finality of goal, and individual (but not family) counseling - were widely available in Swiss outpatient agencies. These interventions were also available in about one quarter to one third of the inpatient programmes, and information on CD was available in almost $60 \%$ of such programmes. Several interventions, however, including group counselling, cue exposure and wet houses were not commonly available in either inpatient or outpatient services in Switzerland.

\section{Reported Bases for the Acceptance or Rejection of Controlled Drinking}

As table 4 shows, respondents from inpatient programmes emphasized mainly their professional experience (73\%) and institutional mission statement (71\%) as important bases for accepting or rejecting CD. Over $90 \%$ of the outpatient treatment programme respondents reported basing their acceptance or rejection of $\mathrm{CD}$ on professional experience (91\%), and two thirds (66\%) noted that research findings influenced their attitudes regarding nonabstinence goals. Neither inpatient nor outpatient directors commonly reportedly relying on their own personal drinking experience as a basis for offering CD.

\section{Sources of Information on Controlled Drinking}

When asked about the sources of information upon which their views of $C D$ are based, over two thirds of the 
programme directors reported that staff members had attended presentations at conferences and a little over one quarter had sent staff to specific CD training courses. Only a small minority, $12 \%$, had not informed themselves at all on the topic.

\section{Discussion}

This national survey of Swiss inpatient and outpatient addiction treatment agencies provides the first explicit data on attitudes and practices regarding controlled drinking in a country known for its innovative interventions to reduce drug-related harm [e.g. 18]. CD was widely acceptable as a therapeutic objective, although there were some differences between the types of treatment settings, with outpatient agencies being more accepting of $\mathrm{CD}$ than inpatient programmes. Swiss services rated $\mathrm{CD}$ as more acceptable when the client was described as misusing alcohol rather than being dependent upon alcohol. These results are similar to those reported in surveys of British, Australian and Norwegian treatment providers $[4,5,8,9]$, who were generally more open to $C D$ than North American respondents [1,3].

Similarly to previously published studies surveying other countries [e.g. 5, 7], Swiss respondents rated certain client characteristics - such as pregnancy, severity of drinking problem, physical health, psychiatric history, and social stability - as important considerations when judging a client's suitability for controlled drinking. The present survey also found that a combination of professional experience, research, and agency philosophy were rated as influencing the acceptance or rejection of $\mathrm{CD}$ and, notably, personal drinking experience was very rarely endorsed as a basis for one's attitudes regarding CD.

The relatively high acceptance of $\mathrm{CD}$ as an outcome goal by Swiss outpatient agencies was matched by widespread availability of interventions such as providing information about $\mathrm{CD}$, willingness to offer $\mathrm{CD}$ as both an intermediate and final outcome goal, and individual counselling in these settings. The lower level of acceptance of $\mathrm{CD}$ in inpatient programmes was reflected by more limited availability of such interventions in those settings. Group CD counselling and cue exposure therapy were not generally available regardless of setting type, perhaps because both clients and clinicians prefer oneon-one therapy and are unfamiliar with cue exposure therapy. Providing clients a 'wet house' service, where they may consume their own alcohol in a safe environment (drinking under control not to be confused with the
Table 2. Relative importance attributed to potential client characteristics when recommending CD, by type of setting

\begin{tabular}{|c|c|c|}
\hline & $\begin{array}{l}\text { In- } \\
\text { patients } \\
\% \\
(\mathrm{n}=62)\end{array}$ & $\begin{array}{l}\text { Out- } \\
\text { patients } \\
\% \\
(\mathrm{n}=74)\end{array}$ \\
\hline Pregnancy does not matter when recommending CD & 17 & 11 \\
\hline $\mathrm{CD}$ recommended when not pregnant & 70 & 84 \\
\hline $\mathrm{CD}$ recommended when pregnant & 13 & 5 \\
\hline Degree of severity does not matter with CD recommendation & 32 & 22 \\
\hline CD recommended when low severity (multiple response) & 58 & 70 \\
\hline CD recommended when medium severity (multiple response) & 18 & $38^{\mathrm{a}}$ \\
\hline CD recommended when high severity (multiple response) & 11 & 6 \\
\hline Psychiatric history does not matter with CD recommendation & 32 & 26 \\
\hline $\mathrm{CD}$ recommended with minor or medium psychiatric history & & \\
\hline (multiple response) & 38 & 54 \\
\hline $\begin{array}{l}\text { CD recommended with severe psychiatric history } \\
\text { (multiple response) }\end{array}$ & 9 & 3 \\
\hline Physical harm does not matter with CD recommendation & 36 & $18^{\mathrm{b}}$ \\
\hline CD recommended in early stage (multiple response) & 59 & $77^{\mathrm{c}}$ \\
\hline CD recommended in advanced stage (multiple response) & 6 & 15 \\
\hline CD recommended in far advanced stage (multiple response) & 4 & 3 \\
\hline Deviant behavior does not matter with CD recommendation & 36 & 37 \\
\hline CD recommended when not deviant (multiple response) & 54 & 60 \\
\hline CD recommended when deviant (multiple response) & 9 & 5 \\
\hline Social stability does not matter with CD recommendation & 38 & 29 \\
\hline $\begin{array}{l}\text { CD recommended when high social stability } \\
\text { (multiple response) }\end{array}$ & 48 & 62 \\
\hline CD recommended with medium social stability & & \\
\hline (multiple response) & 23 & $44^{\mathrm{d}}$ \\
\hline CD recommended with low social stability multiple response & 7 & 4 \\
\hline \multicolumn{3}{|l|}{ Treatment experience does not matter with } \\
\hline CD recommendation & 47 & 59 \\
\hline $\begin{array}{l}\text { CD recommended with previous outpatient experience } \\
\text { (multiple response) }\end{array}$ & 15 & 12 \\
\hline $\begin{array}{l}\text { CD recommended with no previous treatment experience } \\
\text { (multiple response) }\end{array}$ & 24 & 27 \\
\hline CD recommended with previous inpatient only or & & \\
\hline outpatient and inpatient experience (multiple response) & 26 & $11^{\mathrm{e}}$ \\
\hline \multicolumn{3}{|l|}{ Alcohol problems in client's family do not matter with } \\
\hline CD recommendation & 69 & 71 \\
\hline CD recommended when no alcohol cases in the family & 29 & 26 \\
\hline CD recommended when alcohol cases in the family & 2 & 4 \\
\hline Age does not matter with CD recommendation & 83 & $96^{\mathrm{f}}$ \\
\hline CD recommended when 18 to 30 years (multiple response) & 5 & 3 \\
\hline CD recommended when 31 to 50 years (multiple response) & 9 & 3 \\
\hline $\begin{array}{l}\text { CD recommended when older than } 50 \text { years } \\
\text { (multiple response) }\end{array}$ & 12 & 1 \\
\hline Gender does not matter with CD recommendation & 95 & 100 \\
\hline CD recommended for male patients & 5 & 0 \\
\hline
\end{tabular}

${ }^{a-f}$ Proportions offering this service differed significantly $(\mathrm{p} \leq 0.05)$ for outpatient vs. inpatient agencies.

Question read: Regardless if your institution offers CD or not, please tell us under which conditions you would support the wish of the client to pursue $\mathrm{CD}$ as therapeutic objective.

${ }^{\mathrm{a}} \chi^{2}=6.202$; d.f. $=1 ; \mathrm{p}=0.013 ;{ }^{\mathrm{b}} \chi^{2}=4.819 ;$ d.f. $=1 ; \mathrm{p}=0.028 ;{ }^{\mathrm{c}} \chi^{2}=$ 4.094; d.f. $=1 ; \mathrm{p}=0.043 ;{ }^{\mathrm{d}} \chi^{2}=5.924 ;$ d.f. $=1 ; \mathrm{p}=0.015 ;{ }^{\mathrm{e}} \chi^{2}=4.885$; d.f. $=$ $1 ; \mathrm{p}=0.027 ;{ }^{\mathrm{f}} \chi^{2}=6.010 ;$ d.f. $=1 ; \mathrm{p}=0.014$.

$\min (n=111) ; \max (n=126)$ considering missing values. 
Table 3. CD-related treatment services by treatment sector in Switzerland 2005 ( $n=138$; multiple responses allowed)

\begin{tabular}{|c|c|c|}
\hline & $\begin{array}{l}\text { In- } \\
\text { patients } \\
\%\end{array}$ & $\begin{array}{l}\text { Out- } \\
\text { patients } \\
\%\end{array}$ \\
\hline $\begin{array}{l}\text { 'Wet places' ('Alkistübli') where clients with alcohol } \\
\text { problems can consume the alcohol they bring along }\end{array}$ & 7 & 1 \\
\hline $\begin{array}{l}\text { Presentation of drinking cues (e.g. alcoholic beverages, } \\
\text { alcohol-related photos or videos) which trigger craving } \\
\text { and can be addressed to train resistance when confronted } \\
\text { with this stimulus in the future) }\end{array}$ & 20 & 11 \\
\hline Information on $\mathrm{CD}$ as a treatment objective/option* & 57 & $90^{\mathrm{a}}$ \\
\hline $\begin{array}{l}\text { Offer of CD as intermediate objective on the way to total } \\
\text { abstinence for alcohol misusers* }\end{array}$ & 33 & $88^{\mathrm{b}}$ \\
\hline Offer of CD as final objective for alcohol misusers* & 38 & $81^{\mathrm{c}}$ \\
\hline $\begin{array}{l}\mathrm{CD} \text { as treatment objective for diagnosed alcohol misusers } \\
\text { without a preceding period of abstinence* }\end{array}$ & 23 & $77^{\mathrm{d}}$ \\
\hline $\begin{array}{l}\text { Offer of CD as intermediate objective on the way to total } \\
\text { abstinence for dependent patients* }\end{array}$ & 23 & $80^{\mathrm{e}}$ \\
\hline CD as final objective for dependent patients* & 26 & $64^{\mathrm{f}}$ \\
\hline $\begin{array}{l}\text { CD as treatment objective for diagnosed alcohol-depen- } \\
\text { dent patients without a preceding period of abstinence* }\end{array}$ & 10 & 53 \\
\hline Individual CD counselling/therapy proposing $\mathrm{CD}^{*}$ & 54 & $87^{g}$ \\
\hline Group CD counselling/therapy proposing CD & 15 & 24 \\
\hline
\end{tabular}

* Proportions offering this service differed significantly $(\mathrm{p} \leq 0.05)$ for outpatient vs. inpatient agencies.

Item read: Please tick 'yes' or 'no' for each of the therapeutic interventions listed below if service is currently offered by your program.

${ }^{\mathrm{a}} \chi^{2}=2.010$; d.f. $=1 ; \mathrm{p}=0.000 ;{ }^{\mathrm{b}} \chi^{2}=4.244$; d.f. $=1 ; \mathrm{p}=0.000 ;{ }^{\mathrm{c}} \chi^{2}=$ 2.519; d.f. $=1 ; \mathrm{p}=0.000 ;{ }^{\mathrm{d}} \chi^{2}=3.262$; d.f. $=1 ; \mathrm{p}=0.000 ;{ }^{\mathrm{e}} \chi^{2}=4.627$; d.f. $=$ $1 ; \mathrm{p}=0.000 ;{ }^{\mathrm{f}} \chi^{2}=1.882 ;$ d.f. $=1 ; \mathrm{p}=0.000 ;{ }^{\mathrm{g}} \chi^{2}=1.734 ;$ d.f. $=1 ; \mathrm{p}=0.000$.

concept of $\mathrm{CD}$ ), is still rare even though, since the study has been conducted, some cities have added such programs to their services (e.g. the city of Olten).

The widespread acceptance of controlled drinking as an outcome goal is consistent with a general trend toward consumer-oriented and individualized treatment in Switzerland [19] and other countries [20]. For example, 41\% of the respondents endorsed statements that the wish of the patient to pursue $\mathrm{CD}$ should be respected under all circumstances, and only $6 \%$ expressed the view that patients' wishes to moderate their drinking should be rejected under all circumstances. Respecting client's preferences does not obviate professional responsibility, however, and we recommend an informed consent procedure to review the likelihood of a client accomplishing $\mathrm{CD}$, the risks and benefits of both $\mathrm{CD}$ and abstinence, and the choice of interventions designed to support both out-
Table 4. Respondents' basis for acceptance or rejection of controlled drinking therapy by type of setting

\begin{tabular}{|c|c|c|c|c|}
\hline \multirow{3}{*}{$\begin{array}{l}\text { Decision has been made } \\
\text { on the basis of ... }\end{array}$} & \multicolumn{4}{|c|}{ Treatment sector } \\
\hline & \multicolumn{2}{|c|}{ inpatients } & \multicolumn{2}{|c|}{ outpatients } \\
\hline & $\%$ & $\mathrm{n}$ & $\%$ & $\mathrm{n}$ \\
\hline Disease model & 50 & 31 & 45 & 33 \\
\hline Research results ${ }^{\mathrm{a}}$ & 40 & 25 & 66 & $49^{*}$ \\
\hline Professional experience ${ }^{b}$ & 73 & 45 & 91 & $67^{*}$ \\
\hline Personal drinking experience & 5 & 3 & 4 & 3 \\
\hline Mission statement of the institution ${ }^{c}$ & 71 & 44 & 45 & $33^{*}$ \\
\hline
\end{tabular}

* Proportions offering this service differed significantly ( $\mathrm{p} \leq$ 0.05 ) for outpatient vs. inpatient agencies.

Question read: Regardless if your program offers CD as treatment objective, on what bases has the decision to offer or not to offer CD treatment been made?

${ }^{\mathrm{a}} \chi^{2}=9.119 ;$ d.f. $=1 ; \mathrm{p}=0.003 ;{ }^{\mathrm{b}} \chi^{2}=7.488$; d.f. $=1 ; \mathrm{p}=0.006 ;$ ${ }^{\mathrm{c}} \chi^{2}=9.553$; d.f. $=1 ; \mathrm{p}=0.002$.

comes. Furthermore, we recognize that agencies are only one voice in outcome goal negotiation, and that physicians, relatives and employers of clients with drinking problems may not approve of CD [21], and may reject a client's goal choice even if an agency or therapist are open to such an objective.

There are several methodological issues that may limit the conclusions drawn from these results. Firstly, the survey was written to assess agency practices and, although some respondents consulted with their staff as they completed the instrument, respondents may have represented their own views as much or more than those of their colleagues. Secondly, respondents may have different interpretations of what it means to report $\mathrm{CD}$ as an acceptable outcome goal, with some perhaps indicating it is acceptable for clients to express such a preference and others indicating it is acceptable to help clients who want to moderate their drinking, nonetheless reserving the option of counselling specific clients to abstain given their particular history. We recognize that reported alcohol treatment practices may reflect both what occurs at an agency as well as how the respondent wants the agency to be perceived.

In addition, although the response rate was quite good (61\%) for surveys of this type [21,22], a meaningful proportion of Swiss agencies did not participate in this study. To the degree that non-responding agencies employ different policies and practices with their clients, our results may overestimate or underestimate the acceptance of 
controlled drinking. These limitations notwithstanding, given the relatively large proportion of respondents from across the nation, we believe these results represent the current state of acceptance of $\mathrm{CD}$, client characteristics considered relevant to recommending $\mathrm{CD}$, and availability of therapies to assist Swiss clients moderate their drinking. The availability of a wide range of treatment options and objectives including $\mathrm{CD}$ can be assumed to be useful both from an individual and a public health perspective.

For many alcohol misusers the options to choose CD or to alternate between abstinence and CD may increase the acceptance of services and reduce treatment-related stigma.
Finally, the concept of the treatment response on a continuum which mirrors the continuum of problem severity might improve the current low outreach and coverage of treatment services in most countries with about two thirds of the potential treatment populations never having sought help [20].

\section{Acknowledgements}

This project was financed by the Swiss Federal Office of Public Health in co-operation with the Swiss Federal Commission of Alcohol Problems (EKA). Grant No. 02.001548/2.24.02-184 and No. 04.001356/2.24.02-184.

\section{References}

1 Rosenberg H, Davis LA: Acceptance of moderate drinking by alcohol treatment services in the United States. J Stud Alcohol 1994;55: 167-172.

2 Rush BR, Ogborne AC: Acceptability of nonabstinence treatment goals among alcoholism treatment programs. J Stud Alcohol 1986;47:146-150.

3 Rosenberg H, Devine EG, Rothrock N: Acceptance of moderate drinking by alcoholism treatment services in Canada. J Stud Alcohol 1996;57:559-562.

4 Donovan M, Heather N: Acceptability of the controlled-drinking goal among alcohol treatment agencies in New South Wales, Australia. J Stud Alcohol 1997;58:253-256.

5 Dawe S, Richmond R: Controlled drinking as a treatment goal in Australian alcohol treatment agencies. J Subst Abuse Treatment 1997;14:81-86

6 Robertson IH, Heather N: A survey of controlled drinking treatment in Britain. Br J Alcohol Alcoholism 1982;17:102-105.

7 Rosenberg H, Melville J, Levell D, Hodge JE: A 10-year follow-up survey of acceptability of controlled drinking in Britain. J Stud Alcohol 1992;53:441-446.

8 Rosenberg H, Melville J: Controlled drinking and controlled drug use as outcome goals in British treatment services. Addict Res Theory 2005;13:85-92.

9 Duckert F: 'Controlled drinking': a complicated and contradictory field; in Duckert F, Koski-Jannes A, Ronnberg S (eds): Perspectives on Controlled Drinking. Helsinki, Nordic Council for Alcohol and Drug Research, 1989, pp 39-54.
10 Körkel H: Behavioural self-management with problem drinkers: one-year follow-up of a controlled drinking group approach. Addict Res Theory 2006;14:35-49.

11 Maffli E, Kuntsche S, Delgrande JM: Drinking goals of outpatients with alcohol-related problems in the Swiss care supply. 29th Annual Alcohol Epidemiology Symposium of the Kettil Bruun Society for Social and Epidemiological Research on Alcohol, Krakow, 2003.

12 Walters GD: Behavioral self-control training for problem drinkers: a meta-analysis of randomized control studies. Behav Ther 2000; 31:135-149.

13 Rosenberg H: Controlled drinking; in Hersen M, Sledge WH (eds): Encyclopaedia of psychotherapy, New York, Elsevier Science, 2002, pp 533-544.

14 Heather N: Controlled drinking, harm reduction and their roles in the response to alcohol-related problems. Addict Res Theory 2006;14:7-18.

15 Sobell MB, Sobell LC: Controlled drinking after 25 years: how important was the great debate? Addiction 1995;90:1149-1153.

16 Klingemann H, Rosenberg H, Schweizer B, Schatzmann S: Controlled drinking as a tratement objective: a representative survey in Switzerland on the acceptance and implementation of controlled drinking. (Kontrolliertes Trinken als Behandlungsziel - Gesamtschweizerische Umfrage zur Akzep$\operatorname{tanz}$ und Praxisumsetzung). Research Report F03-90. Bern, University of the Applied Sciences, School of Social Work, 2005
17 Act-info Report: Swiss Institute for the Prevention of Alcohol and Other Drug Problems, SFA, 2003

18 Rehm J, Gschwend P, Steffen T, Gutzwiller F, Dobler-Mikola A, Uchtenhagen A: Feasibility, safety, and efficacy of injectable heroin prescription for refractory opioid addicts: a follow-up study. Lancet 2001;358:14171420.

19 Conant D: Drinking Choices, a programme for problem drinkers (Alcochoix, un programme pour consommateur à problèmes). Dependences 2007;17:10-13.

20 Klingemann H, Bergmark A: The legitimacy of addiction treatment in a world of smart people. Addiction 2006;101:1230-1237.

21 Klingemann H, Schatzmann S: Controlled drinking - state of the art and research efforts in Switzerland and selected neighboring countries; in Klingemann $\mathrm{H}$, Room R, Rosenberg H, Schatzmann S, Sobell LC, Sobell MB (eds): Controlled Drinking as Treatment Objective: A Research Inventory. Bern, University of Applied Sciences Bern, School of Social Work, 2004, pp 80-112.

22 Asch DA, Jedrziewski K, Christakis NA: Response rates to mail surveys published in medical journals. J Clin Epidemiol 1997;50: 1129-1136.

23 Cummings SM, Savitz LA, Konrad TR: Reported response rates to mailed physician questionnaires. Health Sci Res 2001;35: 1347-1355 